Job stress and the use of antidepressant medicine: a 3.5-year follow-up study among Danish employees

Thielen, Karsten; Nygaard, Else; Rugulies, Reiner; Diderichsen, Finn

Published in:

Journal of Occupational and Environmental Medicine

DOI:

10.1136/oem.2010.057943

Publication date:

2011

Document version

Early version, also known as pre-print

Citation for published version (APA):

Thielen, K., Nygaard, E., Rugulies, R., \& Diderichsen, F. (2011). Job stress and the use of antidepressant medicine: a 3.5-year follow-up study among Danish employees. Journal of Occupational and Environmental Medicine, 68(3), 205-10. https://doi.org/10.1136/oem.2010.057943 


\title{
Job stress and the use of antidepressant medicine: a 3.5-year follow-up study among Danish employees
}

\author{
Karsten Thielen, ${ }^{1}$ Else Nygaard, ${ }^{1}$ Reiner Rugulies, ${ }^{1,2,3}$ Finn Diderichsen ${ }^{1}$
}

- Additional appendices are published online only. To view these files please visit the journal online (http://oem.bmj. $\mathrm{com} /$ ).

'Department of Social Medicine, Institute of Public Health, University of Copenhagen, Copenhagen, Denmark ${ }^{2}$ Department of Psychology, University of Copenhagen, Copenhagen, Denmark ${ }^{3}$ National Research Centre for the Working Environment, Copenhagen, Denmark

\section{Correspondence to} Karsten Thielen, Department of Social Medicine, Institute of Public Health, University of Copenhagen, Oster Farimagsgade 5, P0 Box 2099, DK-1014 Copenhagen, Denmark;

k.thielen@pubhealth.ku.dk

Accepted 3 September 2010 Published Online First 8 October 2010
ABSTRACT

Objectives To investigate if exposure to adverse psychological job characteristics predicts incident use of antidepressants, taking into account differential misclassification and residual confounding.

Methods A prospective cohort study with a 3.5-year follow-up of 4661 Danish employees, aged 40 and 50 years, drawn from a $10 \%$ random sample of the Danish population was carried out. Job characteristics were the predictor variables and use of antidepressants was the outcome variable. Survey data on psychosocial work environment were linked with register data on dispensing of antidepressant medicine between June 2000 and December 2003. Respondents with major depression at baseline, with antidepressant use in the 5 years preceding baseline, or not employed at baseline were excluded.

Results Among men, the OR for antidepressant use was significantly increased for high quantitative demands (OR $2.12,95 \% \mathrm{Cl} 1.29$ to 3.48) and low social support from colleagues (OR 2.28, 95\% 1.36 to 3.82) after adjustment for lifestyle factors, socio-demographic factors, co-morbidity, other work factors and depressive symptoms at baseline. Both effects were dose dependent. An interaction effect with high demands was found for high anticipated private social support and living with children. Among women, no effect of job characteristics on antidepressant use was found.

Conclusion Among men, but not among women, high quantitative demands and low social support from colleagues were predictive of incident use of antidepressants, indicating incident depressive episodes, even after taking into account differential misclassification and residual confounding. The effects were buffered for those with high anticipated private social support and for those having children.

\section{INTRODUCTION}

Several epidemiological studies have analysed the relationship between psychosocial factors at work and mental health. Two recent reviews conclude that high psychological job demands, low social support and high job strain (a combination of high demands and low decision latitude) in longitudinal studies are associated with depression. ${ }^{12}$ Furthermore, low decision authority, low decision latitude, high job insecurity and job effort-reward imbalance are associated with common mental health problems in general. ${ }^{3}$ Several studies have also shown that work factors might differentially affect men and women.

A major conclusion of the recent reviews is, however, that most studies on work environment and depression are limited by methodological problems-the main issues being misclassification

\section{What this paper adds}

- Several prospective studies have shown that precarious psychosocial work factors may increase the risk of depression.

- Some authors argue that these associations might be seriously inflated because of misclassification and residual confounding.

- Even after adjustment for major sources of misclassification and confounding, this study confirms previous findings on the role of work factors in the aetiology of depression.

- Among men who reported high quantitative demands or low social support, the risk of depression is twice as high as for the unexposed; among women the picture remains less clear.

- At the policy and workplace level, organisational strategies should be initiated that target work overload and promote mutual support between co-workers.

and residual confounding-and that any conclusion regarding causality is vulnerable to these two sources of bias.

\section{Misclassification}

Most studies measure both exposure and outcome by self-administered questionnaires, which is prone to information bias. Differential misclassification is often a major problem, but even when it is non-differential for both exposure and outcome and measurements are made at different times, the errors cannot be regarded as independent. ${ }^{4}$ This is also referred to as the 'common method bias' and might affect the associations in both directions. ${ }^{5}$ Methods for overcoming this problem have included using job exposure matrices and/or register-based measures of outcome such as prescribed antidepressants, standardised mental health interviews or cases of in- and outpatient hospital care for depression. ${ }^{4-11}$ These solutions may, however, introduce other types of misclassification. ${ }^{12}$ Another aspect of exposure misclassification is the fact that induction and exposure time are seldom known and dealt with explicitly.

\section{Residual confounding}

Since the absolute strongest risk factor for depressive episodes in cohort studies is having had earlier episodes, it is crucial to exclude persons with earlier episodes or at least control for this variable. ${ }^{13}$ However, information on earlier episodes is often 
collected by self-report, which might leave some episodes and subclinical depression symptoms unrecorded. It has been shown that mental problems in childhood and early adulthood predict work characteristics in mid-adulthood, and therefore might be confounders. ${ }^{14}$ Personality factors such as neuroticism, as well as current subclinical depression, may influence the way one evaluates the working environment and may be associated with new depressive episodes. ${ }^{1}$ Most studies have controlled for sociodemographic confounders but not for other risk factors for depression, including alcohol intake, family history of depression, chronic somatic disease, private life demands or support and other psychosocial working conditions, which all also might be related to the working characteristics under study.

Some of these possible confounders, for example alcohol intake, might be at least partially caused by the adverse work environment and may therefore be seen as intermediate steps in the causal pathway. Others, like neuroticism, may modify the effect of the work environment.

In the present paper, we set out to study in a cohort design the effect of several adverse work characteristics (high quantitative and emotional work demands, high work pace, low social support from supervisors and colleagues, low sense of workplace community, low meaning of work, low possibilities for development, low variation and high physical demands) on depression. We used register-based incident use of prescribed antidepressant medicine as the outcome measure. We specifically focused on including covariates, which might be potential confounders, mediators or effect measure modifiers, such as socio-demographic factors, lifestyle risk factors, co-morbidity, subclinical depressive symptoms, private life conflicts and private life social support as well as competing work characteristics. We hypothesised that work characteristics at baseline would predict incident antidepressant use during follow-up. We also expected that the effect of high work demands on antidepressant use would be modified by longer job tenure, using this as an indicator of exposure time. Furthermore, we expected that private life demands and resources modify the effect of work demands. ${ }^{15} 16$ Finally, with reference to the diathesis stress theory, we expected persons with subclinical depressive symptoms to be more vulnerable to work stress. ${ }^{1} 17$

\section{METHODS \\ Study design and population}

This is a 3.5-year follow-up study of the effect of different job characteristics on incident use of antidepressant medicine. The Danish Longitudinal Study on Work, Unemployment and Health was designed to investigate the associations between psychosocial factors, unemployment, social marginalisation and health. ${ }^{18}$ Participants were drawn from the Danish Institute of Governmental Research Longitudinal Register. This register includes data on a $10 \%$ random sample of the Danish population aged 15 years or older. From those, a random sample cohort of 11082 Danish residents aged 40 or 50 years old on 1 October 1999, was drawn. The cohort received a postal questionnaire enquiring about psychosocial and ergonomic working conditions, health behaviours, and physical and mental health in March 2000. Overall, 7583 (68\%) respondents completed the survey. The present study dataset was created by linking the baseline survey data with register data on the diagnoses of hospital in- and outpatients during 1968-2000 and on prescribed and purchased antidepressants during 1995-2003 from the Danish Medicinal Product Statistics located at Statistics Denmark and data on individual employment histories from the Institute of Governmental Research Longitudinal Register, also located at Statistics Denmark. The linkage procedure is facilitated by the unique person identification number which is assigned to every resident in Denmark.

Individuals were excluded if at baseline they (a) were not employed, (b) were current or past users (1995-2000) of antidepressants, (c) had a major depression according to the criteria of the Diagnostical and Statistical Manual Version IV (DSM-IV) during the preceding 2 weeks, as assessed by the Major Depression Inventory (MDI) in the survey, (d) had a history of hospitalisation (1968-2000) due to affective disorders or (e) had a missing value on any variable included in the multivariate analyses. The exclusion process resulted in a final sample of 4661 participants. Excluded individuals had a significantly higher likelihood of antidepressant use during follow-up $(6.8 \%)$ than study participants $(4.0 \%)$, as well as a higher frequency of medical histories that included hospital treated mental illness and other co-morbidity. The excluded group contained significantly more women and more people from lower social groups (34\% received social benefits and were outside the labour market). Among the excluded, those defined as exposed regarding job characteristics, had generally higher use of antidepressants.

\section{Definition and measurement of antidepressant use}

Use of antidepressant medicine was defined as being dispensed an antidepressant drug at a pharmacy, which is the only legal way to purchase this type of medicine in Denmark for the nonhospitalised population. Data were retrieved from the Danish Medicinal Product Statistics that contains information on all prescribed medication purchased at pharmacies in Denmark since 1995. We identified registrations for all types of antidepressants (ATC-code N06A), coded after the Anatomical Therapeutic Chemical (ATC) classification system. ${ }^{19}$

'Current or past use of antidepressants' was defined by an entry of N06A in the database at any time between 1 January 1995 and 30 May 2000 (ie, the month after the baseline survey was completed). 'Incident use of antidepressants' was defined by two conditions: (a) an entry of N06A in the database during the 3.5 years of follow-up, which ran from 1 June 2000 to 31 December 2003, and (b) no current or past use of antidepressants. Furthermore, we used as an indicator of the intensity of treatment, the monthly average amount of defined daily doses (DDD) purchased. We separated cases into three groups: (a) those not using antidepressive treatment during follow-up, (b) those using less than or equal to $3.5 \mathrm{DDD}$ per month, and (c) those using more than 3.5 DDD per month (with 3.5 DDD corresponding to the median usage of the sample).

\section{Measurement of job characteristics}

Job characteristics were measured with scales from the Copenhagen Psychosocial Questionnaire, which has been used in several Danish and international studies. A comprehensive description of the instrument and its psychometric properties has been presented elsewhere. ${ }^{20}$

All questions about job characteristics had the response options 'Never', 'Sometimes', 'Often' and 'Always'. Respondents who answered anything other than 'Never' or 'Sometimes' to work demand questions (work pace, quantitative demands, emotional demands, physical demands) and answered anything other than 'Often' and 'Always' to resource questions (social support from superiors, social support from colleagues, meaning of work, opportunities for development, variation of work, sense of community) were classified as being exposed to an adverse 
psychosocial work environment. For quantitative job demands (three questions), physical job demands (four questions), meaning of work (three questions), possibilities for development (three questions), which were covered with more than one question, only those persons who answered at least half of the questions have been included in the analysis. We calculated average answering scores based on the number of questions answered. The midpoint of the scale was used as the threshold for classification of exposure. For the specific wording of all questions, see online supplementary appendix 1.

\section{Definition and measurement of covariates}

As covariates, we assessed gender, age, cohabitation, socioeconomic position (SEP), heavy alcohol consumption, smoking, obesity, depression score at baseline, prior mental illness, co-morbidity other than mental health issues, lifestyle factors, private life conflicts and private life social support, and job tenure as well as the already described work characteristics. Moreover, we used the covariate 'employment during 2000' as a crude indicator of changed employment status during the first year of the follow-up in order to control for the effect of this.

These covariates were selected because they have been associated with risk of depression or use of antidepressants in earlier studies and are therefore possible confounders, mediators or effect modifiers. For more detailed information about the covariates, see online supplementary appendix $2 .^{21-34}$

\section{Statistical analysis}

All analyses were conducted with the statistical program package SAS 9.0. Covariates were analysed for confounding or effect modifying effects on the exposure-outcome relationship for all work demands through single stratified analyses and Cochran-Mantel-Haenszel as well as Breslow-Day statistics. Potential effect modifiers with a significant effect on the exposure-outcome association $(\mathrm{p}<0.05)$ were used for further analysis. $^{35}$ The hypothesised roles of the variables in the analytical model are shown in online supplementary appendix 3 .

The effect of work characteristics at baseline on the risk of incident use of antidepressant medicine during follow-up was measured by ORs and 95\% CIs using multivariate logistic regression models separately for men and women.

Employing incident use of prescribed antidepressants as a measure of depression introduces other problems of misclassification compared to self-reported information. In an earlier study on the same cohort, we analysed the sensitivity and specificity of this misclassification for different subgroups according to age, sex and socio-economic group, using the MDI as the 'gold standard'. ${ }^{12}$ In the present study we used this same method to check the final results for the effect of differential misclassification according to the relevant work exposure variables.

To control for the effects of the covariates, we used three models. Model 1 was adjusted for gender, age, family status, SEP, alcohol consumption, smoking, physical activity, obesity, private life conflicts and anticipated private life social support, and history of mental as well as non-mental co-morbidity at baseline. Model 2 was further adjusted for work characteristics other than the work exposure under study. Because of the high intercorrelation of the single demand and resource scales $(\gamma$ coefficient $0.36-0.92)$, we only adjusted demand scales for resource scales and resource scales for demand scales, but not demand scales for other demand scales and not resource scales for other resource scales. Model 3 was adjusted for depressive symptoms at baseline, using the MDI score as a continuous variable. For the illustration of the effect modification/interaction effects we constructed combined variables of work exposure and the given covariate. Interaction, as departure from multiplicity, was controlled for by including interaction terms in the logistic models.

\section{RESULTS}

The frequencies of adverse work characteristics were different for men and women. The difference was significant for most factors under study, except for 'low meaning of work', 'low opportunities for development' and 'low variation of work'. The prevalence of exposed persons varied from around 5\% for 'low meaning of work' to over $70 \%$ for 'low social support from superiors'. Table 1 shows all sample characteristics at baseline for men and women.

Approximately $4 \%$ of the study population had at least one incident registration for antidepressants during the 3.5 years of follow-up, with higher incidence for women than for men (tables 2 and 3). The logistic regression analysis of the female subsample showed that only low 'meaning of work' was a significant predictor in the crude model, but not after having controlled for further covariates in the other models (table 2). For men, there were significant associations for 'quantitative demands', 'social support from colleagues' and 'low meaning or variation of work' in the crude model. Similar to that observed for women, the association between 'low meaning' and co-morbidity and social position was no longer significant when the variables in model 1 were controlled for. On the other hand, in men, the OR for 'quantitative demands' and 'social support from colleagues' increased as an effect of social position (which

Table 1 Sample characteristics at baseline

\begin{tabular}{|c|c|c|c|c|}
\hline \multirow[b]{2}{*}{ Sample characteristics } & \multicolumn{2}{|c|}{ Men $(n=2439)$} & \multicolumn{2}{|c|}{$\begin{array}{l}\text { Women } \\
(\mathrm{n}=2222)\end{array}$} \\
\hline & $\mathbf{n}$ & $\%$ & $\mathbf{n}$ & $\%$ \\
\hline Group aged 40 years & 1243 & 51.0 & 1224 & 55.1 \\
\hline Group aged 50 years & 1196 & 49.0 & 998 & 44.9 \\
\hline Executive managers, leading managers & 817 & 33.5 & 574 & 25.8 \\
\hline Non-manual salaried employees & 632 & 25.9 & 713 & 32.1 \\
\hline Manual skilled and unskilled workers & 990 & 40.6 & 935 & 42.1 \\
\hline Heavy alcohol consumption & 604 & 24.8 & 511 & 23.0 \\
\hline Smokers & 910 & 37.3 & 751 & 33.8 \\
\hline High physical activity & 645 & 26.5 & 383 & 17.2 \\
\hline Obesity & 270 & 11.1 & 178 & 8.0 \\
\hline Non-mental health morbidity & 1049 & 43.0 & 1046 & 47.1 \\
\hline Muscular-skeletal pain & 383 & 15.7 & 471 & 21.2 \\
\hline Living alone without children & 323 & 13.2 & 252 & 11.3 \\
\hline Partnership without children & 637 & 26.1 & 603 & 27.1 \\
\hline Living alone with children & 42 & 1.7 & 161 & 7.3 \\
\hline Partnership with children & 1437 & 58.9 & 1206 & 54.3 \\
\hline Low private life social conflicts & 198 & 8.1 & 204 & 9.2 \\
\hline Low private life social support & 245 & 10.1 & 190 & 8.6 \\
\hline Job tenure less than 1 year & 394 & 16.2 & 243 & 10.9 \\
\hline High quantitative demands & 642 & 26.3 & 489 & 22.0 \\
\hline High work pace & 1022 & 41.9 & 1012 & 45.5 \\
\hline High emotional demands & 282 & 11.6 & 410 & 18.5 \\
\hline Low social support from colleagues & 1065 & 56.3 & 1166 & 47.5 \\
\hline Low social support from superiors & 624 & 74.4 & 812 & 63.5 \\
\hline Low sense of community & 379 & 15.5 & 252 & 11.3 \\
\hline Low meaning of work & 130 & 5.3 & 93 & 4.2 \\
\hline High physical demands & 185 & 7.6 & 110 & 5.0 \\
\hline Low opportunity for development & 269 & 11.0 & 265 & 11.9 \\
\hline Low variation of work & 492 & 20.2 & 465 & 20.9 \\
\hline
\end{tabular}


Table 2 ORs (95\% Cls) of works factors in 2000 for incident use of antidepressants between 2000 and 2003, women

\begin{tabular}{llllll}
\hline Work characteristic & Antidepressant (\%) & Crude & Model 1* & Model 2† \\
\hline High quantitative demands & $25(5.1)$ & $1.23(0.77$ to 1.95$)$ & $1.08(0.66$ to 1.75$)$ & $1.06(0.65$ to 1.73$)$ & $0.95(0.57$ to 1.56$)$ \\
High work pace & $47(4.6)$ & $1.11(0.74$ to 1.66$)$ & $1.03(0.68$ to 1.55$)$ & $0.99(0.65$ to 1.51$)$ & $0.91(0.60$ to 1.39$)$ \\
High emotional demands & $24(5.9)$ & $1.46(0.91$ to 2.34$)$ & $1.36(0.83$ to 2.22$)$ & $1.30(0.79$ to 2.16$)$ & $1.10(0.65$ to 1.85$)$ \\
Low social support from colleagues & $47(4.5)$ & $1.02(0.68$ to 1.53$)$ & $1.02(0.68$ to 1.55$)$ & $1.06(0.70$ to 1.60$)$ & $1.00(0.66$ to 1.52$)$ \\
Low social support from superiors & $69(4.9)$ & $1.39(0.89$ to 2.16$)$ & $1.40(0.89$ to 2.19$)$ & $1.40(0.89$ to 2.18$)$ & $1.27(0.80$ to 1.99$)$ \\
Low sense of community & $16(6.4)$ & $1.56(0.90$ to 2.71$)$ & $1.48(0.84$ to 2.61$)$ & $1.43(0.81$ to 2.52$)$ \\
Low meaning of work & $8(8.6)$ & $2.13(1.00$ to 4.54$)$ & $1.97(0.90$ to 4.30$)$ & $1.98(0.90$ to 4.33$)$ & $1.18(0.66$ to 2.11$)$ \\
High physical demands & $7(6.4)$ & $1.51(0.68$ to 3.34$)$ & $1.52(0.67$ to 3.46$)$ & $1.46(0.64$ to 3.36$)$ & $1.38(0.59$ to 3.59$)$ \\
Low opportunity for development & $14(5.3)$ & $1.24(0.70$ to 2.22$)$ & $1.31(0.71$ to 2.43$)$ & $1.32(0.71$ to 2.46$)$ & $1.14(0.61$ to 2.15$)$ \\
Low variation of work & $27(5.8)$ & $1.46(0.93$ to 2.31$)$ & $1.53(0.93$ to 2.51$)$ & $1.54(0.93$ to 2.55$)$ & $1.39(0.84$ to 2.31$)$ \\
\hline
\end{tabular}

*Controlled for lifestyle, social relationships, co-morbidity and socio-demographic factors.

†Controlled for lifestyle, social relationships, co-morbidity and socio-demographic factors plus all other work environment factors.

$\ddagger$ Controlled for lifestyle, social relationships, co-morbidity, socio-demographic factors and all other work environment factors plus Major Depression Inventory score.

is the only co-variate in model 1) with a confounding effect of around $10 \%$. Controlling for other work factors also raised the ORs for 'quantitative demands', 'social support', 'low variation', 'low meaning' and 'low opportunity for development' (table 3). In the fully adjusted model 3 , only high 'quantitative demands' and low 'social support from colleagues' significantly increased the odds of antidepressant use for men $(\mathrm{OR} \approx 2)$, although not for women. The interaction between gender and work characteristics, tested as departure from multiplicity, was significant $(p<0.05)$ for both variables. All OR estimates decreased compared to model 2 as an effect of the supplemental adjustment for subclinical depressive symptoms.

For 'quantitative demands', the OR increased with increasing exposure quartiles from 1.03 (95\% CI 0.42 to 2.53$)$ at the first quartile, to 2.38 (95\% CI 1.46 to 4.91$)$ at the second quartile and finally to 3.35 (95\% CI 1.60 to 7.03 ) at the fourth quartile, compared to the first quartile as reference. For 'low social support from colleagues', which had a prevalence of $56 \%$, the dose-effect gradient was less visible with similar ORs for the third (OR 5.00; 95\% CI 1.19 to 21.03) and fourth (OR 5.01; 95\% CI 0.96 to 26.23) exposure categories. Testing for trend showed that trends were significant $(p<0.05)$ in the fully controlled model for both job characteristics. We did not find any differential effect of the highest exposure category of high work pace and social support from superiors.

Dividing the use of antidepressants into low and high average DDD during follow-up, showed that for respondents with a higher than average use, the only statistically significant association was with high 'quantitative demands' (OR 3.06; $95 \%$ CI 1.53 to 6.11). On the other hand, we found significantly increased odds for low 'social support from colleagues' for respondents taking a lower than average monthly dose (OR 3.29 ; $95 \%$ CI 1.31 to 8.29 ).

Only the covariates 'anticipated private life social support' and 'living together with children' significantly modified the effect of high quantitative demands on subsequent antidepressant use, although they had no effect on the associations with emotional demands or work pace. Neither job tenure nor subclinical depression symptoms significantly modified the effect of job demands. The combination of high 'quantitative demands' and low 'private life social support' increased the OR for antidepressant use to 2.31 (95\% CI 1.15 to 4.20), whereas the combination with 'high private life social support' did not (OR $1.18 ; 95 \%$ CI 0.82 to 1.71$)$. The test for interaction as departure from multiplicity was significant $(p<0.05)$ in the controlled logistic regression model. Furthermore, the effect of high 'quantitative demands' was modified by 'living together with children'. For those 'living with children', there was no effect of 'quantitative demands' (OR 1.05; 95\% CI 0.67 to 1.63), whereas for those not 'living with children' and experiencing work demands, the OR was increased to 1.48 (95\% CI 0.92 to 2.40). Testing for interaction again showed a significant effect $(\mathrm{p}<0.05)$.

\section{DISCUSSION}

In men but not women, self-reported high 'quantitative demands' and 'low social support from colleagues' increased the OR of incident use of antidepressants during the 3.5 years of follow-up. After controlling for a variety of possible residual confounders, including subclinical depressive symptoms, the ORs remained significant. Both effects were dose dependent. The effect of 'quantitative demands' was attenuated for those

Table 3 ORs (95\% Cls) of works factors in 2000 for incident use of antidepressants between 2000 and 2003, men

\begin{tabular}{|c|c|c|c|c|c|}
\hline Work characteristic & Antidepressant (\%) & Crude & Model 1* & Model 2† & Model 3‡ \\
\hline High quantitative demands & $35(5.5)$ & $2.06(1.32$ to 3.21$)$ & $2.36(1.47$ to 3.81$)$ & $2.46(1.51$ to 4.01$)$ & 2.12 (1.29 to 3.48$)$ \\
\hline High work pace & $40(3.9)$ & $1.27(0.82$ to 1.97$)$ & $1.18(0.75$ to 1.86$)$ & $1.16(0.74$ to 1.84$)$ & $1.11(0.70$ to 1.77$)$ \\
\hline High emotional demands & $11(3.9)$ & $1.16(0.61$ to 2.21$)$ & 1.04 (0.53 to 2.03$)$ & 1.07 (0.54 to 2.13$)$ & 0.88 (0.43 to 1.77$)$ \\
\hline Low social support from colleagues & $63(4.6)$ & $2.39(1.45$ to 3.94$)$ & $2.48(1.49$ to 4.12$)$ & 2.51 (1.50 to 4.18$)$ & 2.28 (1.36 to 3.82$)$ \\
\hline Low social support from superiors & $69(3.8)$ & $1.60(0.91$ to 2.83$)$ & $1.66(0.93$ to 2.94$)$ & $1.66(0.93$ to 2.95$)$ & $1.48(0.83$ to 2.65$)$ \\
\hline Low sense of community & $19(5.0)$ & $1.62(0.96$ to 2.73$)$ & $1.66(0.96$ to 2.86$)$ & $1.60(0.92$ to 2.79$)$ & $1.28(0.72$ to 2.26$)$ \\
\hline Low meaning of work & $9(6.9)$ & $2.22(1.08$ to 4.53$)$ & $2.02(0.97$ to 4.22$)$ & $2.16(1.02$ to 4.56$)$ & $1.46(0.66$ to 3.21$)$ \\
\hline High physical demands & $7(3.8)$ & $1.11(0.51$ to 2.45$)$ & 0.89 (0.39 to 2.03$)$ & $0.85(0.37$ to 1.99$)$ & $0.66(0.28$ to 1.61$)$ \\
\hline Low opportunity for development & $14(5.2)$ & 1.65 (0.91 to 2.97$)$ & $1.58(0.84$ to 2.97$)$ & $1.76(0.93$ to 3.33$)$ & $1.48(0.77$ to 2.84$)$ \\
\hline Low variation of work & $25(5.1)$ & 1.71 (1.06 to 2.76$)$ & $1.55(0.94$ to 2.56$)$ & 1.67 (1.00 to 2.78$)$ & $1.55(0.92$ to 2.62$)$ \\
\hline
\end{tabular}

*Controlled for lifestyle, social relationships, co-morbidity and socio-demographic factors.

†Controlled for lifestyle, social relationships, co-morbidity and socio-demographic factors plus all other work environment factors.

$\ddagger$ Controlled for lifestyle, social relationships, co-morbidity, socio-demographic factors and all other work environment factors plus Major Depression Inventory score. 
experiencing a lack of 'anticipated private life social support' and for those not 'living with children'. Analysis of the exposureoutcome timing indicated a stronger effect for those with shorter exposure length before baseline measurement.

Virtanen et al find the same increase in antidepressant use for high job demands in men. ${ }^{11}$ The two reviews on work environment and depression that mainly include studies using indicators for depression other than antidepressant use, similarly find high job demands to be a risk factor, but without any clear gender difference. ${ }^{12}$ Sinokki et al in a Finnish cohort study also find low social support from colleagues and supervisors to be risk factors for subsequent antidepressant use for both genders. ${ }^{10}$ These results, however, have to be viewed with caution, because they were neither adjusted for baseline depressive symptoms nor for prior antidepressant use. Bonde et al in a Danish cohort study measure adverse work characteristics at the work unit level. ${ }^{36}$ Municipality work units with low social support are predictive of new prescriptions of antidepressants. The result is weakened by the fact that it is not consistent with findings in the county work units. In our study 'quantitative demands' but not 'work pace' predicted antidepressant use. This result might indicate that it is the perceived imbalance between the allocated working time and the time required to complete work tasks that affects mental health rather than high 'work pace' only.

The effects were gender specific with regard to use of antidepressants, in contrast to studies using depression rating scales as the measure of outcome. An explanation might be that women cope differently with work stress or seek help at an earlier stage. This might result in treatment other than pharmaceutical medication for those with depressive symptoms. It is also possible that health professionals evaluate and respond to stressful work characteristics differently for men and for women. In both cases, the real associations would be underestimated or overlooked because exposed cases would be misclassified. Furthermore, men and women might evaluate the severity of adverse work characteristics differently, something we cannot control for in this study. If we accept average use of antidepressants as a crude indicator of the intensity of treatment, low social support from colleagues is predictive of low intensity treatment only. Keeping in mind that in accordance with international guidelines, antidepressant treatment for depression needs to last for about 3 months, this association might be the result of a lack of treatment efficacy, adverse effects or medical treatment inadequate in other ways. ${ }^{37}$ The analysis of the modifying effect of private life factors showed that a lack of 'anticipated private life social support' increased the effect of high 'quantitative demands'. This underscores the importance of taking into account the interplay between private and work life demands and resources and is in line with the results of other studies. $^{15} 1638$ Interestingly, 'living together with children' reduced the effect of high work demands in our sample, which may have indicated a buffer effect, rather than children being an additional source of demands, which has been more commonly discussed. $^{15}$

\section{Strengths and limitations}

The study used a cohort design in order to assess new disease episodes thoroughly, and excluded persons who had had an episode of major depression at baseline and as well as those who had used antidepressants during the preceding 5.5 years. Furthermore, we were able to adjust for the baseline MDI score as an indicator for subclinical depression symptoms or distress, which in fact had the strongest attenuating effect on the exposure-outcome association. In principle, depressive symptoms might also be a result of job stress occurring before the baseline measurement. In such a case, job stress would be a mediator and our analysis would have underestimated the real associations by controlling for it. Based on the available data, it is not possible to determine the exact role of job stress prior to baseline, but it is possible that both its confounding effect and its mediating effect are taking place at the same time. The resulting 'true' values would lie somewhere between those of models 2 and 3 . With this in mind, it would be relevant to discuss low variation of work and low meaning of work as further potential risk factors for incident use of antidepressants in men.

The results of the final logistic regression model were additionally controlled for a variety of potential confounders. None of them substantially affected the exposure-outcome association. This variety of covariates gave an opportunity to test private life factors for their potential role as effect modifiers. The choice of antidepressant used as an indicator of depression in this study countered the 'common method bias', which otherwise threatens analysis by inflating associations. At the same time this choice introduced another misclassification problem, because not all depressed persons receive medical treatment and antidepressants are prescribed for reasons other than depression. This latter means that our measurement of depression is imprecise, but except for a limited use of antidepressants to treat somatic chronic pain, all other indications are also related to mental ill-health. ${ }^{39}$ In another study using the same data, we analysed the degree and direction of differential misclassification that occurs when using antidepressants as an indicator of major depression and integrated an adjustment method to compensate for the bias. ${ }^{12}$ Using this method, that is adjusting for differential misclassification across levels of exposure, did not change the direction of the two crude main effects in the present study. On the contrary, the adjusted estimates suggest that the results of this study were an underestimation of the real effects.

The study was limited by the selection and quality of work environment measures. In particular, questions about control over work were missing, which prevented us from analysing the demand-control concept. As in other studies which use survey data to measure work factors, exposure measurement is very limited. Unknown duration of exposure makes it impossible to study the dose-response association adequately. We used 'job tenure', with change of job title as indicator for length of exposure, under the assumption that exposure will increase along with 'job tenure'. We had no knowledge about the concrete exposure situation before baseline, which made this indicator quite imprecise, covering also selection processes dependent on factors other than how much time has been spent in the workplace. The study was limited to persons aged 40 and 50 years at baseline, which also confined the potential generalisability of its results to these age groups. This is a limitation because it is possible that psychosocial exposures have different effects at different stages of life. Through the exclusion process we lost approximately $38 \%$ of the sample. As there was higher use of antidepressants among the exposed portion of the excluded respondents, it seems likely that the exclusion process had the effect of weakening the studied associations.

\section{Concluding remarks}

From a public health perspective, the results of this study lead to several conclusions. In men, self-reported high 'quantitative demands' and low 'social support from colleagues' are work stressors with high prevalence in the Danish work force, and contribute to the development of depression episodes and other 
manifestations of mental ill health requiring antidepressant treatment. ${ }^{40}$ Especially at risk are men who report high 'quantitative demands' and at the same time lack a supportive social environment within their private network. To better understand gender differences pertaining to these associations, further work is necessary that can prospectively measure mental illness independently of treatment. This would make it possible to differentiate between the effect of work stressors on mental health and on health service utilisation.

Funding This study was supported by grants from the Danish Working Environment Research Fund (grant numbers: 24-2005-09, 2-2006-04 and 5-2006-04) and the Ministry of Health and Prevention, Public Health Fund (grant number: 2005-14033-8).

Competing interests None

Ethics approval The study has been notified to and registered by the Danish Data Protection Agency (Datatilsynet, see http://www.datatilsynet.dk). According to Danish law, studies that include data from questionnaires and from registers only do not need approval from the Danish National Committee on Biomedical Research Ethics (Den Centrale Videnskabsetiske Komité, see http://www.cvk.sum.dk/).

Provenance and peer review Not commissioned; externally peer reviewed.

\section{REFERENCES}

1. Bonde JP. Psychosocial factors at work and risk of depression: a systematic review of the epidemiological evidence. Occup Environ Med 2008;65:438-45.

2. Netterstrom B, Conrad N, Bech P, et al. The relation between work-related psychosocial factors and the development of depression. Epidemiol Rev 2008;30:118-32

3. Stansfeld S, Candy B. Psychosocial work environment and mental health-a metaanalytic review. Scand J Work Environ Health 2006;32:443-62.

4. Podsakoff PM, MacKenzie SB, Lee JY, et al. Common method biases in behavioral research: a critical review of the literature and recommended remedies. J Appl Psychol 2003;88:879-903.

5. Thoresen M. A note on correlated errors in exposure and outcome in logistic regression. Am J Epidemiol 2007:166:465-71.

6. Wieclaw J, Agerbo E, Mortensen PB, et al. Psychosocial working conditions and the risk of depression and anxiety disorders in the Danish workforce. BMC Public Health 2008;8:280.

7. Niedhammer I, Chastang JF, Levy D, et al. Study of the validity of a job-exposure matrix for psychosocial work factors: results from the national French SUMER survey. Int Arch Occup Environ Health 2008;82:87-97.

8. Kessler RC, Ustun TB. The World Mental Health (WMH) Survey Initiative Version of the World Health Organization (WHO) Composite International Diagnostic Interview (CIDI). Int J Methods Psychiatr Res 2004;13:93-121.

9. Kouvonen A, Oksanen T, Vahtera J, et al. Low workplace social capital as a predictor of depression: the Finnish Public Sector Study. Am J Epidemiol 2008;167:1143-51.

10. Sinokki M, Hinkka K, Ahola K, et al. The association of social support at work and in private life with mental health and antidepressant use: the Health 2000 Study. J Affect Disord 2009;115:36-45.

11. Virtanen $\mathbf{M}$, Honkonen $\mathrm{T}$, Kivimaki $\mathrm{M}$, et al. Work stress, mental health and antidepressant medication findings from the Health 2000 Study. J Affect Disord 2007;98:189-97.

12. Thielen K, Nygaard E, Andersen I, et al. Misclassification and the use of register-based indicators for depression. Acta Psychiatr Scand 2009;119:312-19.

13. Burcusa SL, lacono WG. Risk for recurrence in depression. Clin Psychol Rev 2007:27:959-85.

14. Stansfeld SA, Clark C, Caldwell T, et al. Psychosocial work characteristics and anxiety and depressive disorders in midlife: the effects of prior psychological distress. Occup Environ Med 2008;65:634-42.

15. Ertel KA, Koenen KC, Berkman LF. Incorporating home demands into models of job strain: findings from the work, family, and health network. J Occup Environ Med. 2008:50:1244-52.
16. Frone MR. Work-family conflict and employee psychiatric disorders: the National Comorbidity Survey. J Appl Psychol 2000;85:888-95.

17. Stansfeld S. Work, personality and mental health. Br J Psychiatry 2002;181:96-8

18. Christensen U, Lund R, Damsgaard MT, et al. Cynical hostility, socioeconomic position, health behaviors, and symptom load: a cross-sectional analysis in a Danish population-based study. Psychosom Med 2004:66:572-7.

19. Danish Medcines Agency (Laegemiddelstyrelsen). Danish Products Statistics. 2008.

20. Kristensen TS, Hannerz H, Hogh A, et al. The Copenhagen Psychosocial Questionnaire-a tool for the assessment and improvement of the psychosocial work environment. Scand J Work Environ Health 2005;31:438-49.

21. Bjerkeset 0, Romundstad P, Evans J, et al. Association of adult body mass index and height with anxiety, depression, and suicide in the general population: the HUNT study. Am J Epidemiol 2008;167:193-202.

22. Andersen I, Thielen K, Nygaard E, et al. Social inequality in the prevalence of depressive disorders. J Epidemiol Community Health 2009;63:575-8.

23. Haug TT, Mykletun A, Dahl AA. The association between anxiety, depression, and somatic symptoms in a large population: the HUNT-II study. Psychosom Med 2004; 66:845-51

24. Lawlor DA, Hart CL, Hole DJ, et al. Body mass index in middle life and future risk of hospital admission for psychoses or depression: findings from the Renfrew/Paisley study. Psychol Med 2007;37:1151-61.

25. Mykletun A, Overland S, Aaro LE, et al. Smoking in relation to anxiety and depression: evidence from a large population survey: the HUNT study. Eur Psychiatry 2008:23:77-84.

26. Stordal E, Bjartveit KM, Dahl NH, et al. Depression in relation to age and gender in the general population: the Nord-Trondelag Health Study (HUNT). Acta Psychiat Scand 2001:104:210-16.

27. Stordal E, Bjelland I, Dahl AA, et al. Anxiety and depression in individuals with somatic health problems. The Nord-Trondelag Health Study (HUNT). Scand J Prim Health Care 2003;21:136-41.

28. Bech P, Rasmussen NA, Olsen LR, et al. The sensitivity and specificity of the Majo Depression Inventory, using the Present State Examination as the index of diagnostic validity. J Affect Disord 2001;66:159-64.

29. Forsell Y. The Major Depression Inventory versus Schedules for Clinical Assessment in Neuropsychiatry in a population sample. Soc Psychiatry Psychiatr Epidemiol 2005; 40:209-13.

30. Lund R, Modvig J, Due P, et al. Stability and change in structural social relations as predictor of mortality among elderly women and men. Eur J Epidemiol 2000; 16:1087-97.

31. Lund $\mathbf{R}$, Sejbaek CS, Christensen U, et al. The impact of social relations on the incidence of severe depressive symptoms among infertile women and men. Hum Reprod 2009;24:2810-20.

32. Olsen LR, Jensen DV, Noerholm V, et al. The internal and external validity of the Major Depression Inventory in measuring severity of depressive states. Psychol Med 2003;33:351-6.

33. Schatzberg AF. The relationship of chronic pain and depression. J Clin Psychiatry 2004;65(Suppl 12):3-4.

34. Verdu B, Decosterd I, Buclin T, et al. Antidepressants for the treatment of chronic pain. Drugs 2008:68:2611-32.

35. Marshall SW. Power for tests of interaction: effect of raising the Type I error rate Epidemiol Perspect Innov 2007; 4:4.

36. Bonde JP, Munch-Hansen T, Wieclaw J, et al. Psychosocial work environment and antidepressant medication: a prospective cohort study. BMC Public Health 2009;9:262.

37. Malhi GS, Adams D, Porter $\mathrm{R}$, et al. Clinical practice recommendations for depression. Acta Psychiatr Scand Supp/ 2009:8-26.

38. Melchior M, Berkman LF, Niedhammer I, et al. The mental health effects of multiple work and family demands. A prospective study of psychiatric sickness absence in the French GAZEL study. Soc Psychiatry Psychiatr Epidemiol 2007;42:573-82.

39. Demyttenaere K, Bonnewyn A, Bruffaerts $R$, et al. Clinical factors influencing the prescription of antidepressants and benzodiazepines: results from the European study of the epidemiology of mental disorders (ESEMeD). J Affect Disord 2008;110:84-93.

40. Pejtersen JH, Kristensen TS. The development of the psychosocial work environment in Denmark from 1997 to 2005. Scand J Work Environ Health 2009:35:284-93. 


\section{Job stress and the use of antidepressant medicine: a 3.5-year follow-up study among Danish employees}

Karsten Thielen, Else Nygaard, Reiner Rugulies, et al.

Occup Environ Med 2011 68: 205-210 originally published online October 8, 2010

doi: 10.1136/oem.2010.057943

Updated information and services can be found at:

http://oem.bmj.com/content/68/3/205.full.html

\section{These include:}

\section{Data Supplement "Web Only Data" \\ http://oem.bmj.com/content/suppl/2010/10/05/oem.2010.057943.DC1.html \\ References This article cites 38 articles, 11 of which can be accessed free at: http://oem.bmj.com/content/68/3/205.full.html\#ref-list-1}
Email alerting Receive free email alerts when new articles cite this article. Sign up in service the box at the top right corner of the online article.

\section{Notes}

To request permissions go to:

http://group.bmj.com/group/rights-licensing/permissions

To order reprints go to:

http://journals.bmj.com/cgi/reprintform

To subscribe to BMJ go to:

http://group.bmj.com/subscribe/ 